\title{
Papillomavirus Transforming Protein E6
}

National Cancer Institute

\section{Source}

National Cancer Institute. Papillomavirus Transforming Protein E6. NCI Thesaurus. Code C19170.

Binds to and promotes degradation of p53 protein resulting in disruption of cell cycle regulation. 